\title{
O projeto de fundação da ciência da educação: convergências entre Franz Brentano e John Stuart Mill
}

\section{Evandro Oliveira de Brito*}

\begin{abstract}
Resumo
O presente artigo tem como objetivo apresentar a introdução histórica da noção de intencionalidade, tal como ela se deu no âmbito da investigação filosófica e científica acerca da Etologia, ou seja, da ciência da formação do caráter. Nossa estratégia argumentativa consistirá em sustentar que John Stuart Mill, em sua obra Lógica das ciências morais, e Franz Brentano, em sua obra Psicologia do ponto de vista empírico, acordaram explicitamente que a Psicologia seria a ciência das leis elementares da mente e a Etologia seria a ciência que corresponderia à arte da educação no sentido mais amplo. Portanto, o artigo tratará, num primeiro momento, de especificar os pontos convergentes das duas teorias e, num segundo momento, de sustentar que a diferença fundamental entre as Psicologias de Mill e Brentano estava no fato de que a tese de Brentano não reconhecia o pressuposto milliano fundamental de que a relação causal entre fenômenos psíquicos deveria ser o objeto de estudo da Psicologia, a partir do qual as leis psíquicas seriam estabelecidas. A análise mostrará que, para Brentano, o fenômeno psíquico seria, enquanto objeto de estudo da Psicologia, a própria relação fundamental entre fenômenos físicos e fenômenos psíquicos. Esta relação fundamental estaria caracterizada por sua natureza intencional, a qual apresentava a descrição dos fenômenos físicos como conteúdos ou objetos dos fenômenos psíquicos. A consequência desta tese brentaniana implicaria, portanto, que a fundamentação da Etologia também decorreria da investigação da natureza intencional dos fenômenos psíquicos.
\end{abstract}

Palavras-chave: Etologia. Franz Brentano. John Stuart Mill.

\footnotetext{
* Doutor em Filosofia pela Pontifícia Universidade Católica de São Paulo (PUC/SP). Professor da Universidade Estadual do Centro-Oeste (UNICENTRO).
} 


\section{INTRODUÇÃO}

Ainda que seja inegável a enorme distância teórica existente entre as teses filosóficas de fundo desenvolvidas pelos filósofos John Stuart Mill e Franz Brentano, não é possível negar a similitude na relação que ambos estabelecem entre a Psicologia e a Etologia (ciência da formação do caráter). De fato, ainda que Mill e Brentano tenham concebido de modo diverso as especificidades de cada uma dessas ciências, eles estavam plenamente de acordo tanto acerca de suas definições, quando tomadas no sentido mais geral, como acerca da relação de dependência existente entre elas. Em outras palavras, ambos acordaram explicitamente que a Psicologia seria a ciência das leis elementares da mente e a Etologia seria a ciência que corresponderia à arte da educação no sentido mais amplo. Mill, por exemplo, afirmou, na segunda parte de sua obra Sistema de lógica, denominada Lógica das ciências morais (1999 [1872]), que as leis de formação do caráter seriam leis deduzidas a partir das leis gerais da mente. Por sua vez, Brentano afirmou em sua Psychologie vom empirisch Standpunkt [Psicologia do ponto de vista empírico] (1971, 1973 [1874]), citando explicitamente as tarefas delineadas por Mill, que a Psicologia também teria a tarefa de se tornar o fundamento científico de uma teoria da educação, tanto para o indivíduo como para a sociedade. Assim, se a similaridade entre os trabalhos de ambos os filósofos é evidente e declarada textualmente, cabe perguntar pelas especificidades e diferenças existentes entre eles. Esta será, portanto, a pergunta que o presente artigo responderá em quatro partes.

$\mathrm{Na}$ primeira parte, apresentaremos o modo como o filósofo alemão Franz Brentano concebeu, em sua obra Psicologia do ponto de vista empírico, a proposta de fundamentação da Etologia apresentada na obra Lógica das ciências morais, de John Stuart Mill. Na segunda parte, apresentaremos a definição milliana de Psicologia e a distinção entre fenômenos mentais e fenômenos corporais que ela pressupõe. $\mathrm{Na}$ terceira parte, apresentaremos a principal limitação epistemológica que Brentano encontrou na Psicologia de Mill e mostraremos como a noção de relação (ao objeto) intencional foi introduzida por Brentano para solucionar tal limitação. Na última parte, apresentaremos o principal traço da virada brentaniana ao cognitivismo moral e indicaremos, conclusivamente, o problema que levou Brentano a abandonar seu primeiro projeto de fundamentação psíquica da teoria do sentimento moral, bem como de fundamentação da Etologia na sua filosofia do psíquico. De qualquer modo, e ainda que esse tenha sido o projeto inacabado de Brentano, ele teve a virtude de reintroduzir a teoria da intencionalidade, seja por meio do conceito de objeto intencional, seja por meio do conceito de relação intencional, como fundamento da investigação das leis que regem a formação do caráter humano. 


\section{BRENTANO HERDEIRO DE MILL}

Para apresentar o modo como Brentano concebeu a proposta de fundamentação da Etologia millliana, precisaremos contextualizá-la no projeto de fundação das ciências humanas desenvolvido por Mill na sua obra Lógica das ciências morais. Essa contextualização exigirá, especificamente, uma exposição do modo como a psicologia milliana deveria se constituir como ciência, pois a consolidação da Psicologia seria a condição de possibilidade da Etologia também como ciência.

Segundo Brentano, Mill ofereceu uma sinopse, a qual tratou das questões básicas da Psicologia, com o propósito de tornar explícita a sua concepção de ciência psíquica. Esta sinopse estabeleceu três pontos fundamentais.

O primeiro ponto da sistematização de Brentano explicitou que a tarefa geral da psicologia seria a investigação das leis de sucessão dos nossos estados psíquicos. Em outras palavras, a Psicologia trataria de investigar e explicitar as leis segundo as quais um estado psíquico produziria o outro. Esta investigação evidenciaria, portanto, que algumas dessas leis psíquicas seriam gerais e outras, por sua vez, especiais.

De acordo com a interpretação de Brentano, Mill estabeleceu que "uma lei geral, por exemplo, seria a lei que, não importando por que causa dada, toda impressão psíquica tem como consequência um fenômeno semelhante a ela, mas também menos intenso, que poderia ser produzido na ausência da primeira excitação causal" (BRENTANO, 1973, p. 17-18, tradução nossa) ${ }^{l}$.Assim, para usar a linguagem de Hume, Mill teria assumido que cada impressão teria uma ideia e, por isso mesmo, teria assumido que haveria certas leis gerais, as quais determinariam a realização efetiva de tal ideia.

Brentano apresentou as três "leis de associação de ideias", citadas por Mill, do seguinte modo:

a) A lei de semelhança (das Gesetz der Similarität): "as ideias semelhantes buscam estimular-se entre si” (BRENTANO, 1973, p. 18, tradução nossa) ${ }^{2}$.

b) A lei da contiguidade (das Gesetz der Contiguität): “quando dois fenômenos psíquicos tiverem sido experienciados em frequente ligação um com o outro, seja simultaneamente ou em

\footnotetext{
${ }^{1}$ Leia-se no original: “Allgemein z. B. sei das Gesetz, dass jeder psychische Eindruck, gleichviel durch welche Ursache gegeben, zur Folge habe, dass eine ihm ähnliche, wenn auch minder lebendige, Erscheinung in Abwesenheit der zuerst erregenden Ursache hervorgebracht werden könne."

${ }^{2}$ Leia-se no original: "Dass sich ähnliche Ideen einander zu erregen suchen"..
} 
sucessão imediata, e um fenômeno ou a ideia de um fenômeno retorna, ela busca estimular a outra" (BRENTANO, 1973, p. 18, tradução nossa) $)^{3}$.

c) A lei da intensidade (das Gesetz der Intensität): "uma intensidade maior em uma ou em ambas as impressões, no que diz respeito ao mútuo estímulo, é equivalente à maior frequência da conjunção" (BRENTANO, 1973, p. 18, tradução nossa ) ${ }^{4}$.

Após ter destacado, deste modo, a investigação das leis de sucessão dos nossos estados psíquicos como tarefa geral da Psicologia, Brentano passou à delimitação do ponto seguinte.

O segundo ponto da sistematização brentaniana estabeleceu que a Psicologia reivindicada por Mill ainda teria como tarefa deduzir leis mais específicas e mais complexas de pensamento, a partir dessas leis gerais e fundamentais dos fenômenos psíquicos. Assim, nas palavras de Brentano, a questão que Mill estabeleceu para a investigação das leis específicas foi posta do seguinte modo:

Dado que vários fenômenos psíquicos, disse ele, muitas vezes agem em conjunto, então se impõe a pergunta: trata-se ou não, em todos os casos, de uma combinação de causas? Em outras palavras, efeitos e condições prévias relacionam-se sempre, como no campo da mecânica, onde movimento resulta de movimento, homogêneos às causas e em certa medida como sua soma? Ou o campo psíquico exibe também casos similares ao processo de mistura química, onde não são encontrados na água qualquer das características de oxigênio e hidrogênio, e no cinabre qualquer das qualidades características do mercúrio e do enxofre? (BRENTANO, 1973, p. 18, tradução nossa) ${ }^{5}$.

Esta foi, de fato, uma questão complexa, e Brentano destacou dois elementos fundamentais da análise estabelecidos por meio dela. O primeiro desses elementos a ser analisado seria a própria relação causal, ou causação, entre as ideias, conditio sine qua non da formulação de leis ${ }^{6}$. $\mathrm{O}$ segundo elemento seria o tipo de combinação causal, uma vez que, tal como Mill havia estabelecido na primeira parte do seu Sistema de lógica, a Psicologia poderia se valer tanto do método da física como do método da química.

\footnotetext{
${ }^{3}$ Leia-se no original:“Wenn zwei psychische Erscheinungen häufig in Verbindung mit einander erfahren worden sind, sei es gleichzeitig oder auch in unmittelbarer Folge, und die eine oder die Idee der einen Erscheinung, wiederkehrt, sie die der andern zu erregen sucht".

4 Leia-se no original: "Dass grössere Lebendigkeit in dem einen oder in den beiden Eindrücken in Bezug aufgegenseitige Erregung gleichbedeutend mit häufigerer Verhindung ist."

${ }^{5}$ Leia-se no original: "Da oft mehrere psychische Phänomene zusammenwirken, sagt er, so erhebe sich die Frage, ob jeder solche Fall ein Fall der Zusammensetzung von Ursachen sei oder nicht; d. h. ob Folgen und Vorbedingungen sich überall so verhalten, wie auf dem Gebiete der Mechanik, wenn Bewegung aus Bewegungen resultirt, den Ursachen homogen und gewissermassen als ihre Summe; oder ob das psychische Gebiet auch Fälle zeige, ähnlich dem Processe chemischer Mischung, wo an dem Wasser nichts von den Eigenthümlichkeiten des Sauerstoffs und Wasserstoffs, an dem Zinnober nichts von den besondern Eigenschaften des Quecksilbers und Schwefels gefunden wird."

${ }^{6}$ Conferir o capítulo II do livro Lógica das ciências morais, intitulado "Liberdade e Necessidade", onde Mill explicita o seu conceito de causação (ou relação de causa e efeito entre fenômenos), também como objeto das ciências morais, eliminando qualquer ranço das doutrinas fatalista ou necessitaristas.
} 
Segundo a interpretação brentaniana, "o próprio Mill considerava provado que os dois tipos de casos ocorrem no campo dos fenômenos internos" (BRENTANO, 1973, p. 18, tradução nossa) ${ }^{7}$. Em outras palavras, poderia ocorrer algumas vezes um processo análogo ao da mecânica, mas outras vezes poderia ocorrer uma combinação análoga ao da química. Assim, se a relação causal fosse análoga àquela que ocorre na mecânica, os fenômenos psíquicos causariam outros fenômenos psíquicos de modo homogêneo e como soma das causas, tal como o "movimento resulta de movimento, homogêneos às causas e em certa medida como sua soma" (BRENTANO, 1973, p. 18, tradução nossa $)^{8}$. No entanto, poderia ocorrer, também, que a relação causal fosse análoga àquela que ocorre na química. Nesse caso, os fenômenos psíquicos ou representações se fundiriam de modo que já não mais parecessem vários, mas uma representação simples de um tipo completamente diferente. Este seria, portanto, o caso "das representações do extenso e do espaço tridimensional a partir das sensações sinestésicas" (BRENTANO, 1973, p. 19, tradução nossa) ${ }^{9}$.

Assim, tendo explicitado no primeiro ponto aquilo que Mill definiu como objeto da psicologia (leis gerais e especiais, as quais regulam as relações causais que governam a associação dos fenômenos mentais) e, no segundo ponto, a dupla possibilidade metodológica (ou modos de investigação das relações causais análogas à física ou à química), a análise brentaniana avançou mais um passo.

O terceiro ponto da sistematização expôs as funções da Psicologia milliana em dois âmbitos fundamentais. De um lado, estaria o âmbito cognitivo, onde se investigaria tanto os conhecimentos, ou crenças imediatas, como as leis que regulam as inferências válidas. De outro lado, estaria o âmbito emotivo, onde se investigaria os objetos desejados originalmente, bem como as relações causais que determinariam os desejos por coisas originalmente indiferentes ou, até, desagradáveis. Deste modo, disse Brentano acerca desses dois âmbitos estabelecidos pela Psicologia milliana:

No que diz respeito à crença, se investigará quais crenças nós temos imediatamente e, além disso, segundo quais leis uma crença se segue da outra e segundo quais leis um fato é, com razão ou não, tomado como prova para outro. Em relação ao desejo, no entanto, antes de tudo a tarefa é investigar quais objetos nós originalmente e por natureza desejamos e, além disso, então, determinar as causas às quais nos levam a desejar coisas originalmente indiferentes ou, até mesmo, desagradáveis (BRENTANO, 1973, p. 19, tradução nossa) ${ }^{10}$.

\footnotetext{
${ }^{7}$ Leia-se no original: "St. Mill selbst hält es für erwiesen, dass Fälle von beiderlei Art auf dem Gebiete der innern Erscheinungen eintreten".

${ }^{8}$ Leia-se no original: "wenn Bewegung aus Bewegungen resultirt, den Ursachen homogen und gewissermassen als ihre Summe".

${ }^{9}$ Leia-se no original: "die Vorstellung der Ausdehnung und des Raums mit drei Dimensionen aus den Empfindungen des Muskelsinns".

${ }^{10}$ Leia-se no original: "In Betreff des Glaubens werde zu erforschen sein, welchen Glauben wir unmittelbar haben; und weiter, nach welchen Gesetzen ein Glauben den andern erzeuge; und nach welchen Gesetzen eine Thatsache, mit Recht oder Unrecht, als Beweis für eine andere angesehen werde. In Betreff des Begehrens aber werde es vor Allem Aufgabe sein, zu untersuchen, welche Gegenstände wir ursprünglich und von Natur begehren; und weiter dann, die
} 
Retomemos, então, o que foi estabelecido até aqui nos três pontos sistematizados por Brentano, à luz das afirmações apresentadas na citação acima.

Brentano expôs as etapas fundamentais da proposta apresentada por Mill para a fundação das ciências morais. Assim, ficou caracterizada a posição basilar da Psicologia, na medida em que ela explicitaria as leis gerais e especiais, as quais regeriam as associações entre os fenômenos internos, estabelecendo o seu tipo de relação causal a partir de um procedimento metodológico análogo ao da física ou da química.

Portanto, uma vez que a Psicologia estivesse constituída como ciência, estaria aberta a porta para o desenvolvimento tanto de uma teria do conhecimento e de uma lógica como das ciências morais propriamente ditas. As primeiras seriam resultantes da investigação das crenças e das inferências possíveis a partir de suas relações, enquanto as segundas seriam resultantes da investigação dos desejos e volições.

Assim, após apresentar a base epistemológica milliana e definir o campo de investigação das ciências morais, Brentano pode apontar, ainda, o modo milliano de agregar outro rico campo científico. Segundo ele, tratava-se daquele campo da Etologia, ou ciência da formação do caráter, onde "a investigação psicológica começa se entrelaçar com a fisiológica mais do que em qualquer outra parte" (BRENTANO, 1973, p. 19-20, tradução nossa) ${ }^{11}$.

De modo mais objetivo, portanto, a análise brentaniana explicitou que, segundo Mill, o psicólogo também teria a tarefa de investigar até onde a produção de um estado psíquico por outro seria influenciada por estados físicos demonstráveis. Assim, a investigação da relação causal entre alguns dos estados físicos e seus respectivos estados psíquicos constituiria, portanto, o campo da Etologia.

Segundo a análise brentaniana, Mill teria estruturado este campo da seguinte maneira. Em primeiro lugar, teria estabelecido um triplo fundamento para o fato de que pessoas diferentes são diferentemente sensíveis às mesmas causas psíquicas. Deste modo, tais diferenças "poderiam ser fatos originais e últimos, poderiam ser o resultado da história de sua vida interna prévia ou poderiam ser o resultado uma organização física diferente" (BRENTANO, 1973, p. 20) ${ }^{12}$. Assim, a relação causal entre os estados físicos e os estados psíquicos que determinam a formação do caráter de uma pessoa estaria, portanto, determinada não apenas por causas biológicas, mas também por circunstâncias exteriores e pela educação.

\footnotetext{
Ursachen zu bestimmen, welche uns ursprünglich gleichgültige oder sogar unangenehme Dinge zu begehren veranlassen".

11 "Die psychologische Forschung sich mehr als anderwärts mit der physiologischen zu verflechten beginnt".

12 "Sie könne ursprüngliche und letzte Thatsache, sie könne die Folge der Geschichte seines früheren inneren Lebens, und sie könne die Folge einer verschiedenen physischen Organisation sein".
} 
A formação do caráter seria, no entanto, um ponto fundamental da Etologia milliana, o qual Brentano não abordou de modo específico, uma vez que seu interesse teórico estava vinculado principalmente ao âmbito global da Psicologia de Mill, no qual a Etologia se inseria como parte. Nesse sentido, é importante ressaltar o fato de que a possibilidade do estudo científico da formação do caráter foi concebida por Mill como uma consequência direta do seu modo de definir a noção de causalidade como causação, ou seja, como relações causais entre fenômenos, chamadas de leis de associação. Em outras palavras, ao excluir as pressuposições metafísicas que remetiam a noção de causalidade ao fatalismo e ao necessitarismo ${ }^{13}$, Mill teria restringido o campo de investigação da Etologia às relações causais entre fenômenos físicos e mentais, tal como fizera com o campo de todas as ciências morais. Assim, a validade científica das leis etiológicas encontradas empiricamente, as quais governariam as relações causais entre fenômenos constituintes da formação do caráter, decorreria do fato de que tais leis deveriam ser deduzidas das leis psíquicas mais gerais, as quais governariam as relações causais entre todos os fenômenos mentais relacionados aos desejos e volições.

Diante desse quadro conceitual, e tal como Mill o explica na citação a seguir, todo o campo da investigação etiológica estaria constituído sob o pressuposto da liberdade pessoal, a qual se definiria pela capacidade de escolher ou mudar as causas, sempre necessárias, que influenciariam a formação do caráter.

\begin{abstract}
O homem tem, até certo ponto, poder para alterar seu caráter. Que o caráter seja, em última análise, formado para ele não é inconsistente com o fato de ser, em parte, formado por ele como um dos agentes intermediários. Seu caráter é formado por suas circunstâncias (incluindo-se, entre essas, sua organização particular), mas seu próprio desejo de moldá-lo de uma maneira particular é uma dessas circunstâncias e, de nenhuma forma, uma das menos influentes. Nós não podemos, é certo, decidir diretamente ser diferentes do que somos; mas tampouco aqueles que supostamente formaram nosso caráter decidiram diretamente que fôssemos o que somos. Suas vontades só têm poder direto sobre suas próprias ações. O que fizeram conosco o fizeram determinando não os fins, mas os meios necessários; de modo similar, determinando os meios necessários, podemos, quando nossos hábitos não são muito inveterados, modificar-nos. Se eles puderam nos colocar sob a influência de certas circunstâncias, nós, da mesma forma, podemos nos colocar sob a influência de outras circunstâncias. Somos exatamente tão capazes de formar nosso próprio caráter, se quisermos, como os outros são capazes de formá-lo para nós (MILL, 1999, p. 37-38, grifo do original).
\end{abstract}

Essa capacidade, portanto, se caracterizaria como a autonomia de uma pessoa em estabelecer os meios (as circunstâncias) que determinariam necessariamente seu caráter. Tal como afirmou

\footnotetext{
13 "A doutrina do livre-arbítrio, tendo em mente precisamente aquela fração da verdade que o termo Necessidade põe de lado, a saber, o poder da mente para cooperar na formação de seu próprio caráter, deu aos seus adeptos um sentimento prático muito mais próximo da verdade do que aquele que, acredito, geralmente existiu na mente dos Necessitaristas. Estes últimos podem ter um sentido mais vivo de importância daquilo que os seres humanos podem fazer para formar o caráter uns dos outros, mas a doutrina do livre-arbítrio, eu acredito, fomentou em seus partidários um espírito mais forte de cultivo pessoal". (MILL, 1999, p. 39).
} 
Mill, "se examinamos mais de perto, reconhecemos que este sentimento da capacidade de modificar, se quisermos, nosso próprio caráter é o sentimento mesmo da liberdade moral de que temos consciência” (MILL, 1999, p. 38, grifo do original). Ainda segundo ele, a condição para que uma pessoa se sentisse moralmente livre estaria ligada ao fato de que ela não se sentisse dominada por seus hábitos e tentações. Ao contrário, ela se sentiria moralmente livre quando os dominasse, ainda quando tivesse que ceder a eles, mas estando certa de que os resistiria "e que, se desejasse livrar-se deles completamente, não necessitaria, para isso, de um desejo mais forte do que aquele que ela sabe ser capaz de sentir" (MILL, 1999, p. 38).

Uma vez estabelecidos esses dois pressupostos, a saber, a liberdade vigente na formação do caráter e a necessidade vigente na relação causal entre fenômenos físicos e mentais, a conclusão da análise brentaniana se tornou compreensível. Pois, como afirmou Brentano, a Etologia viria a permitir que "o olhar cuidadoso e crítico reconheça que a maior parte do caráter de uma pessoa encontra sua explicação adequada na sua educação e nas circunstâncias exteriores" (BRENTANO, 1973 , p. 20, tradução nossa) ${ }^{14}$.

A parte restante da formação do caráter, que não resultaria nem da educação e nem das circunstâncias exteriores, seria estabelecida, de modo geral, apenas indiretamente pelas diferenças orgânicas. Os exemplos citados para esses casos originados pelas diferenças orgânicas mostravam que essa relação de causalidade seria válida "não apenas para a inclinação à desconfiança que se costuma notar no surdo, à luxúria que se quer costuma notar no cego de nascença e à irritabilidade que se costuma notar no deficiente físico" (BRENTANO, 1973, p. 20, tradução nossa) ${ }^{15}$, mas também, do mesmo modo, para muitos outros casos menos fáceis de conceber.

Finalmente, e ainda segundo a análise brentaniana, nesse mesmo campo assegurado para a Etologia, isto é, para a ciência das leis da construção do caráter, estariam ainda outros fenômenos como, particularmente, os instintos, os quais seriam explicados apenas imediatamente a partir da organização especial.

\section{A PSICOLOGIA DE MILL E AS LEIS DA MENTE}

Exposto o modo com Brentano concebeu a proposta milliana de derivar a Etologia a partir da Psicologia, cabe agora apresentar a definição de Psicologia assumida por Mill, bem como seu objeto de estudo, pois ela explicita a principal limitação epistemológica que a análise brentaniana

\footnotetext{
14 “Der sorgfältig prüfende Blick, meint er, werde erkennen, dass der Charakter eines Menschen seinem bei weitem grösseren Theile nach in Erziehung und äussern Umständen seine adäquate Erklärung finde".

15 "Und offenbar gilt dies in Wahrheit nicht bloss von der Neigung zum Misstrauen, die man bei Tauben, der Lüsternheit, die man bei Blindgebornen, und der Reizbarkeit, die man bei Missgestalteten zu bemerken pflegt".
} 
encontrou. Em outras palavras, ainda que declaradamente comprometido com a proposta milliana, Brentano aceitou a definição de Psicologia como ciência das leis elementares da mente, mas recusou o pressuposto de que a relação causal entre fenômenos mentais seria seu objeto de estudo. Ao confrontarmos, então, as definições de Psicologia apresentadas por Mill e Brentano, explicitaremos como e porque a noção de relação (ao objeto) intencional foi introduzida por Brentano para substituir tal proposta.

Façamos, então, uma exposição da teoria milliana apresentada no capítulo intitulado "As Leis da mente", na obra A Logica das ciências morais (1999).

Segundo Mill, a Psicologia seria definida como aquela ciência que tem "por objeto as uniformidades de sucessão, as leis últimas ou derivadas, de acordo com as quais um estado mental sucede a outro - é causado por outro, ou pelo menos, cuja causa o faz seguir outro estado mental" (MILL, 1999, p. 49). Em outras palavras, a Psicologia seria a ciência que teria leis como objeto, e tais leis poderiam ser de dois tipos distintos, a saber, as leis gerais e as leis especiais, as quais governariam a produção de ideias por meio dos três modos de associação (semelhança, contiguidade e intensidade $)^{16}$. Ao definir a Psicologia dessa maneira, Mill explicitou seu intuito de respeitar os critérios comtianos de cientificidade, ao menos naquilo que se referia à recusa da especulação metafísica. De fato, como ressalta Mill na seguinte citação, não se tratava de uma ciência da mente, onde a mente fosse tomada como um portador substancial, um substrato substancial ou uma coisa em si. Pelo contrário, evidenciava-se principalmente o fato de que os conteúdos dessas relações, ou leis, concebidas pela Psicologia seriam os fenômenos mentais de natureza exclusivamente sensorial ou fenômenos mentais causados pelos fenômenos sensoriais.

\footnotetext{
É alheio às finalidades deste trabalho considerar o que é a Mente, bem como o que é a Matéria ou qualquer outra questão a respeito das Coisas em si mesmas, enquanto distintas de suas manifestações sensoriais. Aqui, como em todo curso de nossa pesquisa, evitaremos todas as especulações a respeito da natureza da mente e entenderemos por Leis da Mente as leis dos fenômenos mentais, dos vários sentimentos ou estados de consciência dos seres que sentem (MILL, 1999, p. 47).
}

Ora, o fato de que a Psicologia milliana investigaria as Leis da mente, concebidas como relações causais de associação, nos conduz imediatamente à pergunta acerca dos conteúdos desses fenômenos mentais que estariam associados de modo causal nessas relações. Em outras palavras, coloca-se a seguinte pergunta: como Mill definiu os fenômenos mentais que existiriam como conteúdos das relações causais?

Segundo ele, tais fenômenos da mente seriam "os vários sentimentos de nossa natureza, tanto aqueles chamados impropriamente de físicos como aqueles particularmente designados de ${ }^{16}$ A este respeito ver Mill (1999, p. 50). 
mentais” (MILL, 1999, p. 47). Neste sentido, disse Mill, “por Leis da Mente eu quero dizer as leis de acordo com as quais esses sentimentos se causam uns aos outros” (MILL, 1999, p. 47). No entanto, nesta definição de fenômenos da mente havia uma imprecisão acerca da natureza "imprópria" do fenômeno físico, a qual foi reconhecida e esclarecida pelo próprio Mill. Segundo ele, a clara distinção entre estados mentais e estados corporais poderia ser estabelecida se o conceito de sensação fosse concebido como um estado ou fenômeno mental, e não como um estado corporal. Assim, tal como elucida as palavras de Mill que se seguem, seria preciso definir o fenômeno mental da sensação, distinguindo-o da sua causa próxima, a qual seria um estado de corpo.

Estes estados (fenômenos mentais), de acordo com a classificação que uniformemente seguimos, consistem em Pensamentos, Emoções, Vontades e Sensações, estes últimos sendo, tanto quanto os anteriores, verdadeiros estados de Mente. Certamente, é usual falar das sensações como estados de corpo e não de mente. Mas isto é um exemplo da confusão comum que consiste em dar um único e mesmo nome ao fenômeno e à causa próxima ou condição deste fenômeno (MILL, 1999, p. 47).

A indistinção recorrente no uso da palavra sensação resultaria, ainda segundo Mill, do fato de não se reconhecer que "o antecedente imediato de sua sensação é um estado de corpo, mas a sensação mesma é um estado de mente" (MILL, 1999, p. 47). Assim, concluiu Mill, "se o termo espírito (mente) quer dizer alguma coisa, ele significa aquele que sente” (MILL, 1999, p. 47). A distinção estabelecida diferenciava, portanto, o estado mental de sentir do estado corporal de sentir, ainda que o estado do corpo antecedesse imediatamente o estado da mente, atuando como sua causa próxima.

Havia, no entanto, outra coisa relevante na caraterização dessa relação causal entre estados mentais e corporais. Tratava-se, ainda, de uma demarcação negativa do objeto de estudo da Psicologia frente à demarcação positiva do objeto de estudo da Fisiologia. Desse modo, tal como evidencia a citação seguinte, Mill apresentou as leis que governariam a relação causal entre estados corporais e mentais como objeto de estudo da Fisiologia. Vejamos.

\footnotetext{
Em relação à aquele estado de mente chamado sensação, todos concordam que eles têm por antecedentes imediatos estados de corpo. Toda sensação tem por causa próxima alguma afecção daquela parte de nosso organismo chamada de sistema nervoso, seja essa afecção originada na ação de algum objeto exterior ou em alguma condição patológica da própria organização nervosa. As leis dessa parte de nossa natureza - as variedades de nossas sensações e as condições físicas de que dependem diretamente - pertencem, manifestamente, à província da fisiologia (MILL, 1999, p. 48).
}

Tendo demarcado, portanto, o objeto de estudo da Psicologia em face do objeto de estudo da Fisiologia, e tendo estabelecido a distinção entre o estado físico de sensação e o estado mental de 
sensação, Mill explicitou a sua classificação dos fatos físicos e dos fatos mentais. Suas palavras, a seguir, resumem esta classificação.

Qualquer que seja a opinião adotada a respeito da identidade ou diversidade fundamental da matéria e da mente, sempre permanecerá, como uma questão de classificação, a distinção entre fatos físicos e mentais, entre o mundo externo e interno e, nesta classificação, as sensações, como todos os outros sentimentos, devem ser colocadas entre os fenômenos mentais. O mecanismo de sua produção, tanto no próprio corpo como naquilo que se designa de natureza externa, é tido como o que podemos, com alguma propriedade, classificar como físico [...] Todos os estados da mente são imediatamente causados ou por outros estados da mente, ou por estados do corpo. Quando um estado da mente é produzido por outro estado da mente, designo a lei concernente ao caso uma Lei da Mente. Quando um estado da mente é produzido diretamente por um estado de corpo, a lei é uma Lei do Corpo e pertence à ciência física (MILL, 1999, p. 47-48).

Concluímos, assim, a sistematização da concepção milliana de Psicologia, pois definimos seu objeto de estudo e especificamos o conteúdo das relações de causa e efeito, as quais serão investigadas no processo de obtenção de leis.

Cabe agora apresentar, pontualmente, a crítica de Brentano à concepção de Psicologia apresentada por Mill e esclarecer o modo como Brentano introduz a noção de intencionalidade, definida primeiramente como relação (ao objeto) intencional e, posteriormente, como relação intencional para com o objeto imanente.

\section{BRENTANO CRÍTICO DE MILL}

A filosofia brentaniana do psíquico, apresentada na obra Psicologia do ponto de vista empírico, em 1874, pretendia fundamentar a ética e a etologia por meio de uma teoria do sentimento moral, a qual estaria comprometida com uma proposta científica, em consequência da sua vinculação ao projeto de J. St. Mill.

No entanto, embora Brentano tenha prometido apresentar sua teoria do sentimento moral em um volume complementar, o qual deveria ter sido elaborado após a publicação da sua principal obra, a Psicologia do ponto de vista empírico (1974), essa promessa nunca foi cumprida. O que temos da sua teoria do sentimento moral é apenas o esboço apresentado na própria obra principal ${ }^{17}$

No que diz respeito aos objetivos que Brentano pretendia alcançar com a sua Psicologia do ponto de vista empírico, ele declarou explicitamente seu comprometimento em obter os mesmos

\footnotetext{
${ }^{17}$ Em 1889, quando publicou a obra Vom Ursprung sittlicher Erkenntnis [Origem do conhecimento moral], Brentano radicalizou sua teoria ética ao abandonar o expressivismo moral e assumir um cognitivismo moral. Embora não seja possível explicar neste trabalho, é interessante ressaltar que um dos fatores que explicariam essa mudança teria sido a reformulação da noção intencionalidade, definida na Psicologia do ponto de vista empírico (1874) como relação (ao objeto) intencional in-existente e, posteriormente na Origem do conhecimento moral (1889), como relação intencional para com o objeto imanente.
} 
resultados almejados por Mill. Tal como indica a passagem a seguir, Brentano citou claramente a proposta milliana apresentada na Lógica das Ciências Morais e a definiu como sua proposta.

\begin{abstract}
Mas isto disse com razão J. St. Mill em sua Lógica das ciências morais: "no que se refere à crença, os psicólogos haverão de investigar sempre mediante estudos específicos e segundo as regras da indução, (a) que crença temos por meio da consciência imediata, (b) que leis regem a gênese de uma crença a partir de outra, (c) em virtude de quais leis uma coisa é considerada como prova de outra para nosso espírito, com razão ou sem ela. No que se refere ao apetite, haverão de investigar, do mesmo modo, (d) que objetos apetecemos primordialmente e (e) que causas nos conduzem a apetecer coisa que são primordialmente indiferentes ou inclusive desagradáveis, etc. (Ded. u. lnd. Logik B. VI, Kap. 4, § 3) (BRENTANO, 1971, p. 68, tradução nossa) ${ }^{18}$.
\end{abstract}

Se, de fato, há identidade nos propósitos de Mill e Brentano, a pergunta que se impõe, agora, indaga pelas diferenças fundamentais entre os pressupostos de ambas as propostas. Em outras palavras se Brentano pretendia apresentar a fundamentação da teoria do conhecimento e da teoria do sentimento moral a partir de outros fundamentos psicológicos, como então ele procedeu e qual a principal diferença apresentada?

A diferença fundamental entre as psicologia de Mill e Brentano estava no fato de que a tese de Brentano não reconhecia a relação causal entre fenômenos psíquicos como sendo o objeto de estudo da Psicologia, a partir do qual as leis psíquicas seriam estabelecidas. Para Brentano, $o$ fenômeno psíquico seria, enquanto objeto de estudo da Psicologia, a própria relação fundamental, caracterizada por sua natureza intencional, a qual ofereceria os fundamentos para a cientificidade da Psicologia ao garantir a evidência de suas leis.

A famosa citação brentaniana, apresentada a seguir, descreve o ponto fundamental da separação teórica entre Mill e Brentano, pois, disse ele:

Todo fenômeno psíquico está caracterizado por aquilo que os escolásticos da idade média chamaram de in-existência intencional (ou mental) de um objeto e que nós chamamos, se bem que com expressões não inteiramente inequívocas, a referência a um conteúdo, a direção a um objeto (pelo qual não se deve entender aqui uma realidade), ou a objetividade imanente. Todo fenômeno psíquico contém algo em si como seu objeto, ainda que nem todos do mesmo modo: na representação há algo representado; no juízo há algo admitido ou rechaçado; no amor, amado; no ódio, odiado; no apetite, apetecido, etc. (BRENTANO, 1971 , p. 124-125, tradução nossa). ${ }^{19}$

\footnotetext{
${ }^{18}$ Leia-se no original: "So sagt denn mit Recht J. St. Mill in seiner Logik der Geisteswissenschaften: In betreff des G1aubens werden die Psychologen immer durch spezifisches Studium nach den Regeln der Induktion zu untersuchen haben, welchen Glauben wir durch unmittelbares Bewußtsein haben, und nach welchen Gesetzen ein Glaube den anderen erzeugt; welches die Gesetze sind; kraft deren ein Ding, mit Recht oder mit Unrecht, von unserem Geiste als Beweis für ein anderes Ding angesehen wird. In bezug auf das Begehren werden sie ebenso zu untersuchen haben, welche Gegenstände wir ursprünglich begehren, und welche Ursachen uns dazu führen, Dinge zu begehren, die uns ursprünglich gleichgültig oder sogar unangenehm sind usw. (Ded. u. Ind. Logik B. VI, Kap. 4, § 3)”.

${ }^{19}$ Leia-se no original: "Jedes psychische Phänomen ist durch das charakterisiert, was die Scholastiker des Mittelalters die intentionale (auch wohl mentale) Inexistenz eines Gegenstandes genannt haben, und was wir, obwohl mit nicht ganz unzweideutigen Ausdrücken, die Beziehung auf einen Inhalt die Richtung auf ein Objekt (worunter hier nicht eine
} 
Esta citação envolve uma grande quantidade de pressupostos que não nos interessa analisar aqui. Trataremos, apenas, de um aspecto, a saber: a caracterização do fenômeno psíquico como relação intencional que se refere a algo já contido no próprio fenômeno psíquico como seu conteúdo ou objeto, ou seja, de modo objetivo.

É fundamental considerarmos, primeiramente, que Brentano chegou a esta definição do conceito de fenômeno psíquico após reformular o clássico conceito de representação, adotando um procedimento de análise muito próximo àquele adotado por Mill para definir o conceito de sensação.

Assim, como expusemos no tópico anterior, um dos pressupostos fundamentais da Psicologia de Mill estava na sua definição de sensação como fenômeno mental. Pois ela colocava como polos opostos de uma mesma relação, por um lado, o fenômeno mental da sensação e, por outro, o fenômeno físico ou corporal que atuaria como sua causa próxima. Deste modo, ainda que distinguida do fenômeno corporal, mas estando imediatamente caracterizada como fenômeno mental, a sensação se constituiria como efeito da relação causal entre estes dois fenômenos. Além disso, apenas como fenômeno mental a sensação estaria relacionada causalmente com outros fenômenos mentais (segundo as leis de associação) e, atendida essa condição, a sensação seria parte do próprio objeto de estudo da Psicologia, a saber, as leis da mente.

Brentano, de modo muito similar, designou a representação como o fenômeno psíquico fundamental. No entanto, o ponto relevante para nossa análise está nas diferenças e não nas similitudes. Assim, ao recusar a clássica definição de representação, Brentano estabeleceu a distinção ente o ato psíquico ou mental de representar e o objeto representado neste mesmo ato. Isto significava que, enquanto atividades da própria sensação, os atos de ver, ouvir, cheirar, tatear ou degustar seriam caracterizados como atos psíquicos ou mentais e definidos como representações. Por outro lado, enquanto correlatos da atividade de sensação, aquilo que estivesse sendo visto, ouvido, cheirado, tateado ou degustado seria caracterizado como objeto contido nos atos psíquicos e definido como conteúdo representado. Deste modo, como ele exemplificou em várias citações, no ato de ver a cor vermelha, a representação consistiria exclusivamente no ato psíquico de ver e, por sua vez, a cor vermelha consistiria no objeto (imanente) visto, enquanto correlato daquele ato psíquico. De modo análogo, no ato de sentir dor, a representação consistiria exclusivamente no ato psíquico de sentir e, por sua vez, a dor sentida consistiria no objeto 
(imanente) sentido, enquanto correlato daquele ato psíquico. Assim, de modo similar à distinção milliana, a representação seria o fenômeno psíquico e o representado seria o fenômeno físico. No entanto, para Brentano haveria algo mais.

Se, como dissemos, Mill concebia a relação entre o fenômeno psíquico e o fenômeno físico a partir da relação causal que descrevia o fenômeno físico como causa próxima do fenômeno psíquico, então a diferença entre sua posição e a de Brentano se explicita. Em outras palavras, ao definir o conceito de fenômenos psíquico e estabelecer seu modo de relação para com o fenômeno físico, Brentano o concebeu como duas partes de uma relação, a saber, a relação (para como o objeto) intencional. Desta maneira, a descrição brentaniana dos fenômenos psíquicos teria sido, portanto, um pouco mais complexa e um pouco mais radical, pois a representação seria apenas um modo de fenômenos psíquico, ainda que fosse o modo mais fundamental.

Descrito como fenômeno psíquico, o conceito de representação assumiu um papel fundamental na teoria brentaniana, pois, disse Brentano, “o objeto primário (correlato do ato) só está presente de um modo necessário e universal na consciência, no modo de inerência (inexistência) intencional que é próprio do ato de representar" (BRENTANO, 1971, p. 127, tradução nossa) ${ }^{20}$. Isto significava que, enquanto fenômeno psíquico, a representação estaria relacionada necessariamente ao fenômeno físico, tendo-o como conteúdo (de um modo objetivo).

Esta foi a tese central de Brentano desenvolvida na Psicologia do ponto de vista empírico, a qual estabeleceu que a Psicologia teria, como objeto de investigação, esta relação (para com o objeto) intencional chamada fenômeno psíquico e, assim, as leis psíquicas estariam fundadas no caráter objetivo desta relação. Comprovaria sua descrição, diz Brentano, o fato de que "[...] é possível pensar sem contradição em um ente que, sem a faculdade do juízo e do amor, estivesse provido apenas da faculdade de representação, mas não o contrário” (BRENTANO, 1971, p. 127, tradução nossa) ${ }^{21}$. Portanto, como já afirmamos em outro trabalho (BRITO, 2013, p. 95), as representações, por si só e ainda que em caráter fictício, permitiriam a inferência de leis que descreveriam essa única atividade psíquica. A inferência destas leis seria aquilo que consolidaria a psicologia como ciência empírica.

Haveria, no entanto, como mencionamos, outras leis que a proposta milliana assumida por Brentano estabeleceu como objetivo da Psicologia. Tratavam-se, assim, das leis da crença (ou do juízo) e das leis do sentimento. Para dar conta destes dois âmbitos do conhecimento, e recusando o

\footnotetext{
${ }^{20}$ Leia-se no original: "Aber wir haben dennoch zugleich einen gewissen Unterschied der Allgemeinheit bemerkt, insofern das primäre Objekt notwendig und allgemein nur in der dem Vorstellen eigenen Weise der intentionalen Einwohnung im Bewußtsein gegenwärtig ist".

${ }^{21}$ Leia-se no orignal: "Auch könnte man sich ohne Widerspruch ein Wesen denken, welches, ohne Vermögen für Urteil und Liebe, allein mit dem Vermögen der Vorstellung ausgestattet wäre, nicht aber umgekehrt".
} 
esquema milliano baseado nas leis de associação, Brentano partiu do pressuposto de que, além da representação, mas tendo-a como base, estariam também o fenômeno psíquico de juízo (ato de julgar) e ofenômenos psíquico de sentimento (ato de amar ou odiar).

Segundo Brentano, entretanto, a descrição dos outros fenômenos psíquicos mostrava que a complexidade de tais fenômenos estava diretamente ligada ao seu grau de dependência. Isso explicava o fato de que, sendo a representação o fenômeno mais simples, ela seria o mais independente.

Ao descrever os fenômenos psíquicos do juízo, Brentano sustentou que seriam atos de afirmação ou negação referidos a um objeto representado. Assim, tratando-se de um tipo complexo de relação (para com o objeto) intencional, todo juízo estaria baseado em uma representação, na medida em que afirmaria ou negaria o objeto representado. Os juízos, deste modo, seriam descritos como aqueles fenômenos relativamente complexos e, por isso, seriam diretamente dependentes dos fenômenos psíquicos de representação, mas seriam independentes dos fenômenos de sentimento. Isto significava, entre outras coisas, que as leis que governariam a atividade psíquica de julgar dependeriam apenas das leis que governariam a atividade psíquica de representar.

Ao descrever os fenômenos psíquicos do sentimento, Brentano sustentou que seriam atos de amor ou ódio referidos a um objeto representado. Assim, tratando-se de um tipo complexo de relação (para com o objeto) intencional, todo sentimento estaria baseado em uma representação, na medida em que apeteceria ou rechaçaria o objeto representado. Segundo o mesmo critério, os sentimentos seriam ainda fenômenos mais complexos e por isso mesmo os mais dependentes. Portanto, suas leis dependeriam diretamente das leis que governariam os juízos, mas também das leis que governariam a atividade de representar.

Tal como as leis psíquicas obtidas a partir da investigação do fenômeno psíquico de representação, a investigação dos fenômenos psíquicos de juízo e dos fenômenos psíquicos do sentimento explicitariam as leis que fundamentariam, por um lado, a lógica e a teoria do conhecimento e, por outro, a teoria do sentimento moral e as ciências humanas em geral. Assim, orientado pela relação (para com o objeto) intencional que é julgado (ou amado e odiado) em um ato psíquico complexo, Brentano substituiu o princípio de leis de associação como fundamento da Psicologia e das ciências morais, tal como havia sido reivindicado por Mill.

\section{BRENTANO E O PROJETO ABERTO PARA UMA ETOLOGIA}

De acordo com o que expusemos, a proposta brentaniana de fundamentação da Etologia estava fundada na sua filosofia do psíquico, a qual tinha por base a noção de relação (para com o 
objeto) intencional. Assim, rompendo definitivamente com Mill, Brentano substituiu o pressuposto associacionista das leis psíquicas, que estabelecia uma relação de causa e efeito entre os fenômenos psíquicos, pela descrição da relação (para como o objeto) intencional que caracterizaria tais fenômenos psíquicos. Tendo esta mudança por base, e ainda que esta tenha se tornado uma promessa não cumprida, a virtude do seu trabalho consistiu precisamente na introdução da noção de intencionalidade, seja na versão de 1874 (como relação - para com o objeto - intencional), seja na versão de 1889 (como relação intencional para com o objeto imanente), pois a introdução dessa noção impôs um novo fundamento para a investigação das leis que regeriam a formação do caráter humano.

Cabe agora, para concluir, expor os principais motivos que teriam tornado a proposta de fundação da Etologia, recepcionada de Mill, uma promessa inviável de ser cumprida por Brentano nos termos apresentados na Psicologia do ponto de vista empírico. Para isso, basta tomar os elementos centrais da teoria brentaniana, de 1874, e analisar os pontos fundamentais que estruturaram sua teoria do sentimento moral, uma vez que essa teoria, que serviria da base para a Etologia, foi abandonada e substituída, em 1889, por uma teoria do cognitivismo moral. Vejamos.

Em primeiro lugar, a teoria brentaniana do sentimento moral pressupunha a unidade da terceira classe de fenômenos psíquicos (sentimento de amor e ódio). Pois com a descrição do fenômeno psíquico de sentimento, Brentano estabeleceu que o ato psíquico de sentir consistiria numa referência ao caráter bom ou mau do objeto intencional in-existente, na medida em que o estatuto ontológico do objeto o constituía como um conteúdo de consciência.

Em segundo lugar, a teoria brentaniana do sentimento moral pressupunha a especificidade de cada modo de referência da consciência ao objeto intencional in-existente. Assim, com a descrição fenômenos de sentimento, Brentano estabeleceu que sua especificidade definiria a experiência do sentimento de amor e ódio como uma experiência valorativa moral e, também, não cognitiva. Deste modo, afirmou Brentano, “[...] acredito que ninguém entenderá minhas palavras como se eu quisesse dizer que os fenômenos desta classe são atos de conhecimento, por meio dos quais se percebe bondade e maldade, valor ou não valor de certos objetos" (BRENTANO, 1973, p. 89, tradução nossa $)^{22}$. Portanto, em 1874 , havia ficado eliminada a possibilidade de conhecimento no âmbito da atividade psíquica do sentimento.

Em terceiro lugar, estaria a promessa não cumprida de descrever a regra de inferência que governaria as leis éticas a partir dos juízos (ou crenças) que determinam o valor moral da vontade.

\footnotetext{
${ }^{22}$ Leia-se no original: "Ich glaube, niemand wird meine Worte so verstehen, als wollte ich sagen, die Phänomene dieser Klasse seien Erkenntnisakte, vermöge deren Güte oder Schlechtigkeit, Wert oder Unwert in gewissen Gegenständen wahrgenommen werde".
} 
Pois, tomando essa regra que se inferiria a partir da relação entre objetos amados, Brentano descreveria a ética como a retidão do amor que se encontrava em conformidade com essa sua regra. Tais regras, uma vez explicitadas pela Psicologia, se constituiriam nas leis da mente a partir das quais seriam deduzidas as leis da Etologia descobertas empiricamente.

Tal como esclarecemos em outro trabalho (BRITO, 2013, p. 120-124), a solução para este último ponto deveria conter duas partes teóricas: $\left(1^{\mathrm{a}}\right)$ uma teoria ética análoga à teoria do silogismo, que Brentano formulou a partir das regras do juízo. Pois tal teoria permitiria descrever a gênese de um amor a partir de outro; e $\left(2^{a}\right)$ as regras que justificariam a validade ou invalidade das inferências de um amor a partir do outro. Estas duas partes teóricas, portanto, comporiam a estrutura da teoria do sentimento moral fundada na filosofia brentaniana do psíquico e seriam a base de toda ciência moral.

Chegamos, então, ao ponto que levou o trabalho de Brentano a uma guinada para o cognitivismo moral, e implicou o abandono do projeto de fundamentação psíquica da Etologia, pois essa proposta teórica apresentada como resposta para as duas questões de J. S. Mill, que o próprio Brentano assumiu, mostraram apenas o seu comprometimento com aquilo que ele classificou como o erro de Aristóteles e confessou, em 1889, não ter percebido no contexto da formulação das suas primeiras obras (BRITO, 2013, p. 124). Esse erro pode ser apresentado a partir dos dois principais pontos que foram corrigidos por Brentano na sua guinada para o cognitivismo moral. Vejamos:

(a) O primeiro ponto seria o erro de pressupor que o fenômeno psíquico do amor é consequência do conhecimento, pois Brentano teria sustentado, em 1874, que "não apenas o representar é notoriamente uma condição prévia da vontade, as crescentes discussões revelam que também o juízo precede ao amor e ao ódio em geral, e mais ainda ao fenômeno relativamente tardio da volição" (BRENTANO, 1973, p. 129, tradução nossa) ${ }^{23}$.

(b) O segundo ponto seria o erro em pressupor que, com base na regra que se inferiria dessa relação, a ética pudesse ser considerada como a retidão do amor que se encontra em conformidade com essa sua regra. Pois Brentano teria afirmado o seguinte, em 1874: "parece inconcebível que um ente esteja dotado com a faculdade do amor e do ódio, sem ter parte na (faculdade) do juízo. Deste modo, é impossível estabelecer lei alguma de sucessão, para este gênero de fenômenos, prescindindo inteiramente dos fenômenos do juízo" (BRENTANO, 1973, p. 128, tradução nossa) ${ }^{24}$.

\footnotetext{
${ }^{23}$ Leia-se no original: "Nicht bloß das Vorstellen ist offenbar eine Vorbedingung des Wollens; die eben geführten Erörterungen zeigen, daß auch das Urteilen dem Lieben und Hassen überhaupt, und um so mehr dem relativ späten Phänomene des Wollens vorgeht"

${ }^{24}$ Leia-se no original: "So scheint es in der Tat undenkbar, daß ein Wesen mit dem Vermögen der Liebe und des Hasses begabt wäre, ohne an dem des Urteiles Teil zu haben. Und ebenso ist es unmöglich, irgendwelches Gesetz der Aufeinanderfolge für diese Gattung von Phänomenen aufzustellen, welches von den Phänomenen des Urteiles gänzlich absieht".
} 
O exposto é suficiente para demarcar as linhas gerais do principal problema enfrentado por Brentano na formulação da sua teoria do sentimento moral e, consequentemente, do abandono de seu primeiro projeto de fundamentação psíquica da Etologia. No entanto, é preciso considerar o fato de que a filosofia do psíquico apresentada por ele, em 1889, teve a pretensão de expor os fundamentos das ciências de modo mais seguro, fundando-os na evidência cognitiva oferecida pela noção de relação intencional para com o objeto imanente. Por isso, nossa análise encerra com a seguinte questão, a qual indaga pela possibilidade da formulação de um caminho científico mais seguro para a Etologia: como a teoria do conhecimento moral, apresentada por Brentano em 1889, reassumiu a proposta de fundamentação da Etologia?

\section{REFERÊNCIAS}

BRENTANO, F. Vom Ursprung sittlicher Erkenntnis. Heusenstamm: Ontos Verlag, 2010. Psychologie vom empirisch Standpunkt. Erster Band. Hamburg: Feliz Meiner, 1973. 
Psychologie vom empirisch Standpunkt. Zweiter Band, Hamburg: Feliz Meiner, 1971.

BRITO, E. O. Psicologia e Ética: o desenvolvimento da filosofia do psíquico de Franz Brentano. Curitiba: CRV, 2013.

A descrição da atividade intencional da consciência na obra psicologia descritiva de Franz

Brentano. Kínesis, Marília, v. IV, n. 7, p. 174-187, 2012. Disponível em: <http://www.marilia.unesp.br/Home/RevistasEletronicas/Kinesis/evandrobrito174-187.pdf>. Acesso em: [08/12/2014].

As implicações éticas na recepção da noção aristotélica de in-existência intencional do objeto na obra "Psicologia do ponto de vista empírico" de Franz Brentano. In: COLÓQUIO HABERMAS: HABERMAS E INTERLOCUÇÕES, VII E SIMPÓSIO NACIONAL DE FILOSOFIA: ÉTICA, FILOSOFIA POLÍTICA E LINGUAGEM, II. Anais... Org. Charles Feldhaus, Eder Soares Santos e José Fernandes Weber. Londrina: UEL, 2011. p. 272-284. Disponível em: $<$ https://www.academia.edu/1287307/As_implicacoes_eticas_na_recepcao_da_nocao_aristotelica_ de_inexistencia_intencional_do_objeto_na_obra_Psicologia_do_ponto_de_vista_empirico_de_Fran z_Brentano>. Acesso em: [08/12/2014].

MILL, S. J. A Lógica das ciências morais. Trad. Alexandre Marssella. São Paulo: Iluminuras, 1999. 
Intentionality, ethology and education:the approaches between John Stuart Mill and Franz Brentano

\begin{abstract}
The point of this paper is to present the historical introduction of the notion of intentionality as it occurred in the context of philosophical and scientific research on the ethology, namely the science of the formation of character. My argumentative strategy will be to maintain that both John Stuart Mill, in his work Logic of the Moral Sciences, and Franz Brentano, in his work Psychology from an Empirical Stand Point, explicitly agreed that psychology would be the science of elementary laws of mind and Ethology would be the science that correspond to art education in the broadest sense. So at first, I will analyze the converging points of both theories and, second, I will argue that the fundamental difference between the Psychologies of Mill and Brentano was the fact that Brentano's thesis did not recognize the fundamental Millian's assumption, i.e., the assumption that the causal relationship between psychic's phenomenon should be the Psychology object of study, from which the psychics' law would be established. My analysis intend to demonstrate that, for Brentano, the psychical phenomenon while matter of study of Psychology, is itself the fundamental relation between physical phenomenon and psychic phenomenon. This fundamental relation would be characterized by its intentional nature, which made explicit the description of physical phenomenon as the content or the object of the psychic phenomenon. The consequence of this brentanian's thesis imply that the theoretical basis of Ethology also result from the investigation of the intentional nature of the psychic phenomenon.
\end{abstract}

Keywords: Ethology. Franz Brentano. John Stuart Mill.

Evandro Oliveira de Brito

E-mail: evandro@unicentro.br
El proyecto de fundación de la ciencia de la educación: convergencia entre Franz Brentano y John Stuart Mill

\section{Resumen}

Este presente artículo tiene como objetivo presentar la introducción histórica de la noción de intencionalidad, tal como se dio en el ámbito de la investigación filosófica y científica acerca de la Etología, es decir, de la ciencia de la formación del carácter. Nuestra estrategia argumentativa consistirá en sostener que John Stuart Mill, en su obra "Lógica de las ciencias morales", y Franz Brentano, en su obra "Psicología desde el punto de vista empírico", despertar explícitamente que la Psicología sería la ciencia de las leyes elementales de la mente Y la Etología sería la ciencia que correspondería al arte de la educación en el sentido más amplio. Por lo tanto, el artículo tratará, en un primer momento, de especificar los puntos convergentes de las dos teorías $y$, en un segundo momento, de sostener que la diferencia fundamental entre las psicologías de Mill y Brentano estaba en el hecho de que la tesis de Brentano no reconocía el presupuesto de la relación causal entre fenómenos psíquicos debería ser el objeto de estudio de la Psicología, a partir del cual las leyes psíquicas serían establecidas. El análisis mostrará que, para Brentano, el fenómeno psíquico sería, como objeto de estudio de la Psicología, la propia relación fundamental entre fenómenos físicos y fenómenos psíquicos. Esta relación fundamental estaría caracterizada por su naturaleza intencional, la cual presentaba la descripción de los fenómenos físicos como contenidos u objetos de los fenómenos psíquicos. La consecuencia de esta tesis brentaniana implicaría, por lo tanto, que la fundamentación de la Etología también se derivaría de la investigación de la naturaleza intencional de los fenómenos psíquicos.

Palabras chabe: Etologia. Franz Brentano. John Stuart Mill.

Enviado em: 08/08/2017

Aprovado em: 11/09/2017 